\title{
Article
}

\section{Development of New Series of Organogelators: N,N',N",N"'-1,2,4,5-Tetra Alkyl/Alkenyl Pyromellitamides}

\author{
Yuichi SAKANISHI", Yusuke NARUSAKA ${ }^{* *}$, Mami ITOH $^{* *}$, Taisuke ARITA ${ }^{* *}$, and Takashi SAEKI ${ }^{* *,}$ \\ ${ }^{*} R \& D$ Center, Organic Chemical Products Company, DAICEL Corporation, \\ Ohtake, Hiroshima 739-0695, Japan \\ ${ }^{* *}$ Graduate School of Science and Engineering, Yamaguchi University, \\ Ube, Yamaguchi, 755-8611, Japan \\ (Received : September 19, 2014)
}

\begin{abstract}
We developed new series of organogelators suitable for industrial use through linkage of the molecular design, synthesis, rheological measurements, and elucidation of the viscosity-increasing mechanism of organic compounds. New organogelators, N,N',N",N"'-1,2,4,5-tetra alkyl/alkenyl pyromellitamides, with four chemical side chains (homocompounds) and two kinds of chemical chains (hetero-compounds) were synthesized. The solubility and rheological properties of synthesized compounds dissolved in seven kinds of organic solvents (oils) were examined by using visual observation, UV spectrophotometry, and rheological measurements. The solubility of the pyromellitamides was improved by controlling the length of the alkyl chains of the hetero-compounds. The hetero-compounds exhibited significant viscoelastic behavior in solution. To investigate the viscosity-increasing mechanism of the synthesized compounds in solution, self-assembled structures formed in solution due to hydrogen bonding among amide groups were observed using transmission electron microscopy. Differential scanning calorimetric analysis and X-ray diffraction analysis were also employed. Finally, we qualified some synthesized compounds as anti-sedimentation agents for titanium (IV) oxide slurry.

Key Words: Organic compounds / Chemical synthesis / Differential scanning calorimetry (DSC) / Self-assembly structure
\end{abstract}

\section{INTRODUCTION}

Rheology control agents for organic solvents (organogelators) have been developed widely over the past decade within the field of hydrophobic-supramolecular materials. ${ }^{1-10)}$ It is well known that certain kinds of surfactants, biopolymers or lowmolecular compounds build self-assembly structures, which intertwine and are then able to capture specific solvents. Several macroscopic observations have been conducted to probe these structures within gels and/or gel-like substances. ${ }^{411)}$ For suitable molecular design of organogelators, the driving force that forms three-dimensional networks like hydrogen bonding, $\pi-\pi$ stacking, or the van der Waals force between molecules should be considered. Low-molecular-weight organogelators constructed from many aromatic rings have been reported (e.g., with biphenyl structure ${ }^{12)}$ and bisurea compounds ${ }^{13)}$ ). Skeleton structures of benzene or cyclohexane with chemical side chains have also been reported as organogelators. Within these compounds, benzene-1,3,5-tricarboxamide behaves as

To whom correspondence should be addressed

E-mail: saeki@yamaguchi-u.ac.jp an effective organogelator for various oils, and the viscosityincreasing property of these oronanogelators may be related to the hydrogen bonds of the amide groups. ${ }^{14)}$ In addition to alkyl groups forming chemical side chains, benzene-1,3,5tricarboxamide with aromatic rings ${ }^{15)}$, alkyl chains with asymmetric carbon ${ }^{16-18)}$, phenylisoxazlyl groups ${ }^{19)}$, alkoxy alkyl groups ${ }^{20)}$, pyridyl groups ${ }^{21)}$, halophenyl groups ${ }^{22)}$, oligo ethylene glycol groups ${ }^{23)}$, and polymer groups ${ }^{24)}$ have also been reported. These derivatives have three of the same groups on the center benzene ring. In addition, a similar compound, 1-acylamino-3,5-bis(2-ethylhexylaminocarbonyl)benzene has been reported to increase the viscosity of a variety of oils with viscoelastic behavior. ${ }^{25,26)}$

Inducing different alkyl chains to the benzene ring with an organogelator is considered to be an effective way to acquire viscoelastic properties in a fluid. Because of the difficulty of the synthesis routes, benzene-1,3,5-tricarboxamide having more than two alkyl groups have been rarely reported. Webb et al. ${ }^{27)}$ and Tong et al. ${ }^{28)}$ synthesized N,N',N",N"'1,2,4,5-tetra alkyl pyromellitamide with four amide groups. The compound showed a similar viscosity-increasing effect to that of tricarboxamide; however, its use was limited 
because of its low versatility for various oils. Controlling crystallinity and solubility in organic solvents is necessary for synthesizing appropriate organogelators. Recently, numerous organogelators are available; however, their uses are normally limited to highly specialized applications. We reported the versatility of seven commercially available organogelators for several organic solvents (oils) together with our newly synthesized organogelators having four alkyl chains to the aromatic ring. 3, 3', 4, 4,' -benzophenone tetracarboxamide. ${ }^{29)}$

In this paper, we synthesized compounds with benzene as a skeleton having four alkyl chains (pyromellitamide), including four varied alkyl amides (homo-compounds) and two different alkyl chains (hetero-compounds). The cost for synthesizing such pyromellitamide organogelators is more reasonable for developing industrial use products than that for benzophenone tetracarboxamide. The solubilities of these compounds to seven kinds of organic solvents were tested, and the viscosity-increasing properties of compounds were qualified by measuring their rheological properties. Morphological observations were conducted together with thermal behavior measurements to consider the mechanism of viscosity-increasing caused by compound molecules. The objective of this study was to develop effective organogelators with high versatility for various oils, to obtain information regarding the linkage of the molecular design, and to conduct rheological evaluation and investigation of the viscosityincreasing mechanism of organic compounds. In an effort to demonstrate the potential relevance of this research to fields like the cosmetic industry, we examined the compounds as an anti-sedimentation agent for titanium(IV) oxide-isododecane slurry, the ingredients of which were similar to ordinary suntan lotion.

\section{EXEPERIMENTAL PROCEDURE}

\subsection{Synthesis of the Organogelators and Preparation of Solutions}

The basic chemical structure of newly synthesized organogelators is pyromellitamide (PMDA-R), as shown in Fig.1. The chemical side chains, R and R', were varied, as shown in Table I, together with compound numbers (1-17). Compounds 1-7 were synthesized from benzene tetracarboxylic acid tetrachloride with an alkylamine and recrystallized. In the case of compounds 8-17, pyromellitic dianhydride was reacted with an alkylamine $\left(\mathrm{RNH}_{2}\right)$, and the amic acid obtained was condensated with an alkylamine $\left(\mathrm{R}^{\prime} \mathrm{NH}_{2}\right)$, adding diisopropyl carbodiimide as a catalyst, and washed with an organic solvent. ${ }^{28)}$ The detailed synthetic method of compound $\mathbf{8}$ is described below as an example:

Oleyl amine ( $7.4 \mathrm{~g}, 28 \mathrm{mmol})$ was added dropwise to a stirred slurry of pyromellitic dianhydride $(3.0 \mathrm{~g}, 14 \mathrm{mmol})$ and pyridine $(20 \mathrm{ml})$ under nitrogen gas at $60{ }^{\circ} \mathrm{C}$. The solution was stirred for $3 \mathrm{~h}$ to produce a homogeneous solution. Diisoprpopyl carbodiimide (7.0 g, $56 \mathrm{mmol}$ ) and 2-ethyllhexyl amine were then added to the solution and stirred for $8 \mathrm{~h}$. The solvent was removed in vacuo to give the crude product as a yellow gel-like material. The crude product was washed with methanol, and the resultant product was filtered to produce compound 8. Compounds 8-17 included a regioisomer of the same amount shown in Fig. 2.

The seven kinds of organic solvents examined in this study were two paraffin oils, three ester oils, and two triglycerides, as indicated in Table II. All solvents were used without further purification. The synthesized compounds were carefully dissolved in the solvents under agitation for $12 \mathrm{~h}$ at $80^{\circ} \mathrm{C}$.

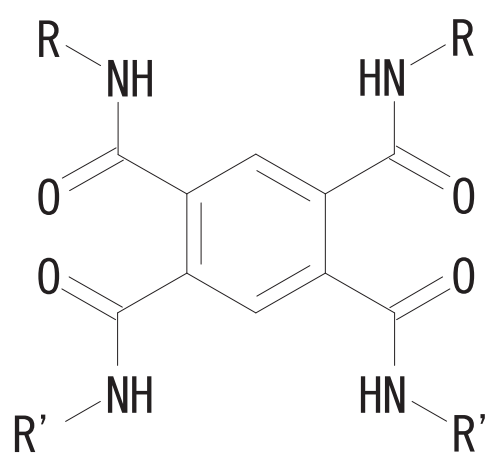

Fig. 1. Chemical structure of PMDA-R.

Table I. Chemical side chains of compounds $\mathbf{1}-\mathbf{1 7}$.

$\left.\begin{array}{ccc}\hline \text { Compound No. } & \mathrm{R} & \mathrm{R} \\ \hline 1 & \text { Oleyl } & \text { Oleyl } \\ 2 & \mathrm{n}-\mathrm{C}_{18} \mathrm{H}_{37} & \mathrm{n}-\mathrm{C}_{18} \mathrm{H}_{37} \\ 3 & \mathrm{n}-\mathrm{C}_{14} \mathrm{H}_{29} & \mathrm{n}-\mathrm{C}_{14} \mathrm{H}_{29} \\ 4 & \mathrm{n}-\mathrm{C}_{12} \mathrm{H}_{25} & \mathrm{n}-\mathrm{C}_{12} \mathrm{H}_{25} \\ 5 & 2 \text {-ethylhexyl } & 2 \text {-ethylhexyl } \\ 6 & \mathrm{n}-\mathrm{C}_{8} \mathrm{H}_{17} & \mathrm{n}-\mathrm{C}_{8} \mathrm{H}_{17} \\ 7 & \mathrm{n}-\mathrm{C}_{6} \mathrm{H}_{13} & \mathrm{n}-\mathrm{C}_{6} \mathrm{H}_{13} \\ 8 & 2 \text {-ethylhexyl } & \text { Oleyl }\end{array}\right]$ Homo-compounds




\subsection{Solubility and Rheological Measurements}

The solubility of the synthesized compounds to the organic solvents was assessed both by visual observation and quantitative evaluation of absorbance at an absorption wavelength in the vicinity of $660 \mathrm{~nm}$, measured by an ultraviolet-visible spectrophotometer (UVmini1240, Simadzu Corporation, Kyoto, Japan). If a sample was cloudy and/or had sedimentation after agitation, we judged the compound to be ineffective for the particular organic solvent.

Rheological properties were measured using a cone and plate rheometer (NRM-2000R, Elquest Corporation, Chiba, Japan). The diameter and angle of the cone were $17.1 \mathrm{~mm}$ and $3^{\circ}$, respectively. The equilibrium flow property was measured for the shear rate range from $0.1-500 \mathrm{~s}^{-1}$. The viscoelastic measurements were conducted at a strain of 0.1 with varying angular frequency of sine wave oscillation from 0.25-34.5 $\mathrm{rad} / \mathrm{s}$. A peltier plate was used to maintain a temperature of $25^{\circ} \mathrm{C}$ during rheological measurements.

\subsection{Characterization}

The self-assembled structure of compound $\mathbf{8}$ was observed by transmission electron microscopy (TEM) (JEM-140, JEOL Corporation, Tokyo, Japan). The organogelator was dissolved in isododecane, and the sample was attached to a support film grid and dried for $2 \mathrm{~h}$. The sample was then

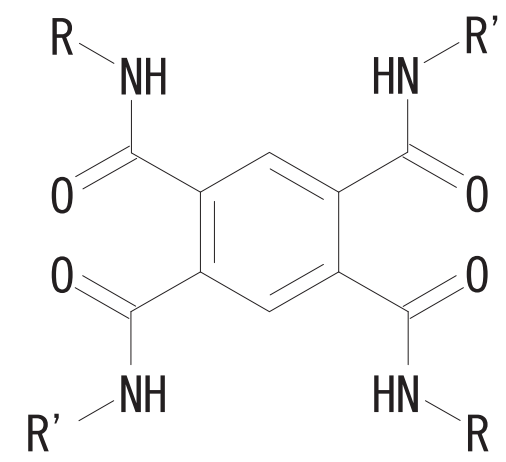

Fig. 2. Regioisomers of hetero-compounds.

Table II. Organic solvents (oils) used in this study.

\begin{tabular}{cc}
\hline Organic solvent & Supplier \\
\hline Liquid paraffin & Moresco Co., Japan \\
Isododecane & Maruzen Petrochemical Co., Japan \\
Isostearyl isostearate & Kokyu Alcohol Kogyo Co., Japan \\
Cetyl 2-ethylhexanoate & Kokyu Alcohol Kogyo Co., Japan \\
2-ethylhexyl isononanate & Kokyu Alcohol Kogyo Co., Japan \\
Tri2-ethylhexanoin & Kao Co., Japan \\
Trioctanoin & Kao Co., Japan \\
\hline
\end{tabular}

stained by osmium tetraoxide $2 \%$ aqueous solution for $4 \mathrm{~h}$. The accelerating voltage of the TEM was $100 \mathrm{kV}$. Calorific values and crystallization temperatures were measured by a differential scanning calorimeter (DSC6200R, Seiko Instruments Corporation, Chiba, Japan). The initial temperature, final temperature, and heating rate were set at $25^{\circ} \mathrm{C}, 350^{\circ} \mathrm{C}$, and $10^{\circ} \mathrm{C} / \mathrm{min}$, respectively. The crystalline characteristics were evaluated by X-ray diffraction spectrum (XRD) analysis. $\mathrm{X}$-ray powder diffraction patterns were recorded for $30 \mathrm{~min}$ (AXS DIP220 with 2D detector, Bruker, Billerica, USA). A monochromatized $\mathrm{Cu}-\mathrm{K} \alpha$ beam $(40 \mathrm{kV}, 250 \mathrm{~mA})$ was transmitted through the sample. The intensity-2 $\theta$ profiles were obtained from the 2-D X-ray diffraction profiles.

\subsection{Stability Evaluation of Titanium(Iv) Oxide - Isododecane Slurries}

Rutile-type titanium(IV) oxide powder (STR-100C-LP) was purchased from the Sakai Chemical Corporation (Osaka, Japan), and used as received. The average primary diameter and density of titanium(IV) oxide particles were $16 \mathrm{~nm}$ and $4270 \mathrm{~kg} / \mathrm{m}^{3}$, respectively. Titanium(IV) oxide-isododecane slurries were prepared by adding $3.53 \mathrm{~g}$ powder to $20 \mathrm{~g}$ isododecane with $0.6 \mathrm{~g}$ lauryl PEG-9 polydimethylsiloxyethyl dimethicone (KF-6038, Shin-Etsu Chemical Corporation, Tokyo, Japan) as a surfactant. Compounds 6 or 8 were examined as anti-sedimentation agents. Thus prepared, $4-\mathrm{cm}^{3}$ slurry was put in a polypropylene container $(\varphi 14 \mathrm{~mm}$ diameter and $40 \mathrm{~mm}$ height) and subjected to centrifugal separation for $5 \mathrm{~min}$. The rotational speed of the centrifuge was varied from 1000-8000 rpm. A sample of the sedimentation layer observed at the bottom of the container was judged to be unstable.

\section{RESULTS AND DISCUSSION}

\subsection{Solubility and Rheology of Synthesized Compounds in Organic Solvents}

Table III shows the solubility results both by visual observation and absorbance measurement for homocompounds (1-7) in the seven organic solvents. A hatched cell in the table indicates poor solubility, in which precipitate of undissolved compound was observed. Dotted cells signify a cloudy appearance (absorbance $<90 \%$ ), while white cells denote a transparent sample (absorbance $>95 \%$ ).

The effects of homo-compounds on the viscosity of isododecane are displayed as equilibrium flow curves (shear viscosity $\eta$ versus shear rate $\dot{\gamma}$ ) in Fig. 3 . We did not conduct any rheological measurements for inferior solubility samples (2-5). Pure isododecane, which has a viscosity of $1.2 \mathrm{mPa} \cdot \mathrm{s}$, 
shows Newtonian properties. Viscosities were increased to 21, 1794, and 2797 times at a shear rate of $10 \mathrm{~s}^{-1}$ with the addition of homo-compounds $\mathbf{1 , 6}$, and 7, respectively, with respect to the original organic solvent. Compounds 6 and 7 presented typical shear thinning properties, which might have been caused by the interaction of compound molecules within the solvent.

The relative viscosities at a shear rate of $10 \mathrm{~s}^{-1}$ for all the solvents with homo-compounds are also shown in Table III. Compound 1 (where four oleyl groups were introduced) showed high solubility for all solvents; however, the relative viscosities were not so high, ranging only from several times to approximately one hundred times. In contrast, compound $\mathbf{5}$

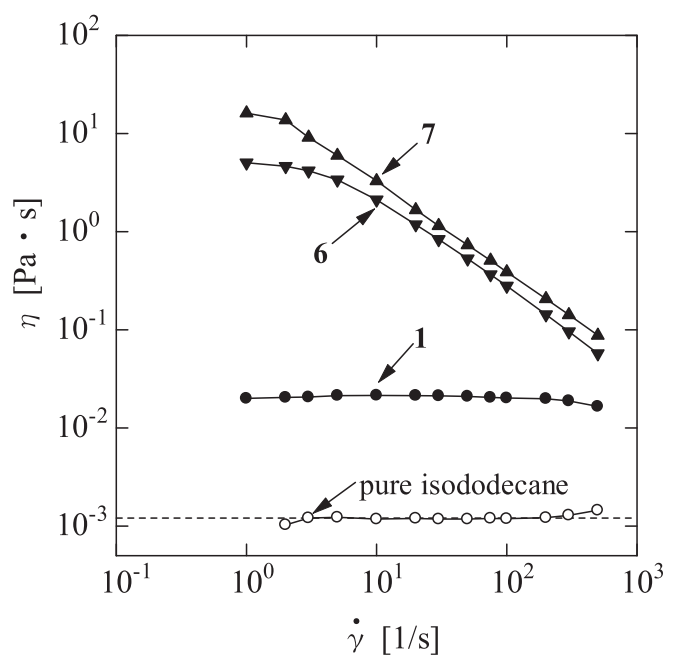

Fig. 3. Equilibrium flow curves for $1 \mathrm{wt} . \%$ synthesized compounds $(\mathbf{1}, \mathbf{6}, \mathbf{7})$ dissolved in isododecane. (four 2-ethylhexyl groups were introduced) did not dissolve for any of the solvents. Compounds 6 and 7 significantly increased the viscosities of isodecane, but did not show a similar effect for other organic solvents. The different levels of both solubility and relative viscosity may be related not only to the affinity of solvents and compounds but also to the expanse of the molecular chains of compounds within the original solvent. Isododecane has the least dipole moment and the least polarizability of all solvents tested; however, we cannot make further deductions from the results shown in this table.

In this study, we tried to control solubility by introducing two different alkyl chains in order to develop more universal gelators. According to the solubility results of the homocompounds mentioned above, a hetero-compound having two 2-ethylhexyl (low-solubility) and two oleyl (high-solubility) was synthesized as compound 8. Moreover, compounds 9-12 introduced two 2-ethylhexyl groups with another two alkyl chains, which were varied from C6 to C18. Compounds 1317 introduced two oleyl groups with another two side chains varied in the same manner. The equilibrium flow properties of the homo-compounds dissolved in isododecane are displayed in Figs. 4 and 5. Again, we did not conduct rheological measurements for inferior solubility samples. All flow curves indicate high relative viscosities and typical shear thinning properties.

The relative viscosities at a shear rate of $10 \mathrm{~s}^{-1}$ for all the solvents with hetero-compounds are shown in Table IV, together with solubility judgments according to visual observation. Significance of cell pattern is the same as in previous tables. Significant improvement of solubility was seen by introducing two kinds of alkyl chains as compared with

Table III. Solubility and relative viscosities of organic solvents with 1 wt. $\%$ homo-compounds (1-7) at $25{ }^{\circ} \mathrm{C}$. Shear rate is $10 \mathrm{~s}^{-1}$. Hatched cell; undissolved, dotted cell; cloudy appearance, white cell; transparent.

\begin{tabular}{|c|c|c|c|c|c|c|c|c|}
\hline \multirow[b]{2}{*}{ Organic solvent } & \multirow{2}{*}{$\begin{array}{l}\text { Solvent } \\
\text { viscosity } \\
(\mathrm{mPa} \cdot \mathrm{s})\end{array}$} & \multicolumn{7}{|c|}{ Synthesized homo-compound } \\
\hline & & 1 & 2 & 3 & 4 & 5 & 6 & 7 \\
\hline $\begin{array}{c}\text { Liquid } \\
\text { paraffin }\end{array}$ & 138.5 & 8 & & & & & & \\
\hline Isododecane & 1.2 & 21 & & & & & 1794 & 2797 \\
\hline $\begin{array}{l}\text { Isostearyl } \\
\text { isostearate }\end{array}$ & 36.9 & 14 & & & & & & \\
\hline $\begin{array}{l}\text { Cetyl 2- } \\
\text { ethylhexanoate }\end{array}$ & 11.8 & 5 & & & & & & \\
\hline $\begin{array}{l}\text { 2-ethylhexyl } \\
\text { Isononanate }\end{array}$ & 4.5 & 11 & & & & & 243 & \\
\hline Tri2-ethylhexanoin & 32.0 & 102 & 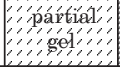 & & & & & \\
\hline Trioctanoin & 22.5 & 93 & & & & & & \\
\hline
\end{tabular}


the homo-compounds. Compound $\mathbf{8}$ showed high solubility for many kinds of oils. Compounds that had 2-ethylhexyl (912) introduced did not dissolve much except in isododecane, which was similar to the results for the homo-compounds discussed above. When oleyl groups were introduced, compounds showed favorable solubility. The viscosityincreasing effect seemed to increase as the length of the alkyl chains decreased. Compounds 9 and $\mathbf{1 3}$ became cloudy solutions for many organic solvents, which may have been due to the high crystalline property of the stearyl group.

The dynamic viscoelastic properties of homo-compound 6 and hetero-compound $\mathbf{8}$ dissolved in isododecane are displayed

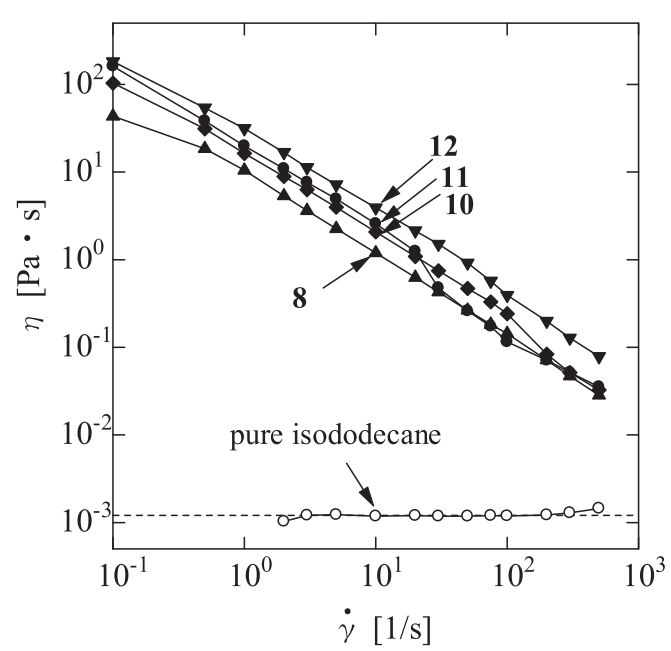

Fig. 4. Equilibrium flow curves for 1 wt.\% synthesized compounds (8, 10-12) dissolved in isododecane. in Fig. 6. Compound 8 exhibited a higher level of $G^{\prime}$ at a lower angular frequency range, indicating longer relaxation time due to the presence of self-assembled structure.

\subsection{Gelation Mechanism Studies}

The morphology of hetero-compound $\mathbf{8}$ was studied by TEM. Fig. 7 shows the image of the compound in isododecane, in which fiber-like molecules with diameters of ca. $10 \mathrm{~nm}$ can be observed. The presence of such selfassembled structures might have contributed to the increased viscosity of the isododecane solution. Figs. 8 (a) and (b) are images of the same compound in trioctanoin, which show

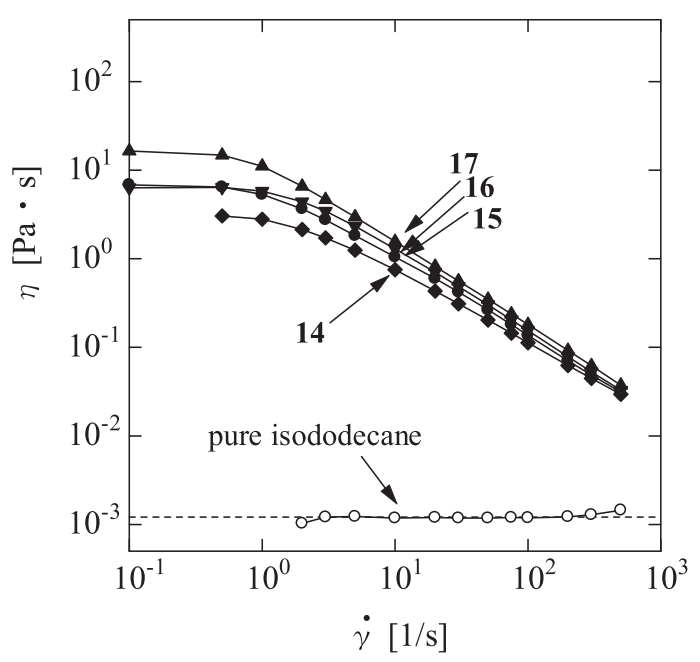

Fig. 5. Equilibrium flow curves for $1 \mathrm{wt} . \%$ synthesized compounds (1316) dissolved in isododecane.

Table IV. Solubility and relative viscosities of organic solvents with 1 wt.\% homo-compounds (8-17) at $25^{\circ} \mathrm{C}$. Shear rate is $10 \mathrm{~s}^{-1}$. Hatched cell; undissolved, dotted cell; cloudy appearance, white cell; transparent.

\begin{tabular}{|c|c|c|c|c|c|c|c|c|c|c|}
\hline \multirow{2}{*}{ Organic solvent } & \multicolumn{10}{|c|}{ Relative viscosity (-) of hetero-compound } \\
\hline & 8 & 9 & 10 & 11 & 12 & 13 & 14 & 15 & 16 & 17 \\
\hline $\begin{array}{c}\text { Liquid } \\
\text { paraffin }\end{array}$ & 21 & & 35 & & & & 17 & 19 & 19 & 22 \\
\hline Isododecane & 1239 & & 1758 & 2185 & 3324 & & 639 & 888 & 1094 & 1324 \\
\hline $\begin{array}{c}\text { Isostearyl } \\
\text { isostearate }\end{array}$ & 60 & 56 & & & & & 50 & 52 & 62 & 72 \\
\hline $\begin{array}{c}\text { Cetyl 2- } \\
\text { ethylhexanoate }\end{array}$ & 129 & & 196 & & & & 59 & 87 & 121 & 155 \\
\hline $\begin{array}{l}\text { 2-ethylhexyl } \\
\text { Isononanate }\end{array}$ & 266 & 331 & 432 & $\begin{array}{l}\text { partial } \\
\text { gel }\end{array}$ & & & 249 & 380 & 418 & 441 \\
\hline $\begin{array}{c}\text { Tri2- } \\
\text { ethylhexanoin }\end{array}$ & 32 & $\begin{array}{l}\text { partial } \\
\text { gel }\end{array}$ & $\begin{array}{l}\text { partial } \\
\text { gel }\end{array}$ & & & & 97 & 115 & $\begin{array}{c}\text { partial } \\
\text { gel }\end{array}$ & 141 \\
\hline Trioctanoin & 8 & $\begin{array}{c}\text { partial } \\
\text { gel }\end{array}$ & & & & & & & $\begin{array}{c}\text { partial } \\
\text { gel }\end{array}$ & 188 \\
\hline
\end{tabular}


entangled thin fibers with diameters of several-hundred $\mathrm{nm}$. Although the compound shows good solubility in the solvent, the ability of viscosity-increasing is not enough.

The dipole moment of isododecane and trioctanoin are $0.03 \mathrm{D}$ and $4.83 \mathrm{D}$, respectively. According to the images of compound $\mathbf{8}$ with isododecane and trioctanoin and their above-mentioned solubility, a schematic view of the relationship between conformation of self-assembled structure and solubility in terms of the polarity (length of alkyl chain) of organogelators and dipole moment of solvents is shown in Fig. 9.

Hanabusa et al. (2009) explained the molecular design of biphenyl type organogelators in terms of their solubility in solvents, self-organizing ability, and the control of crystalline properties. All of these properties are closely related to the thermal behavior of compound molecules. Fig. 10 shows

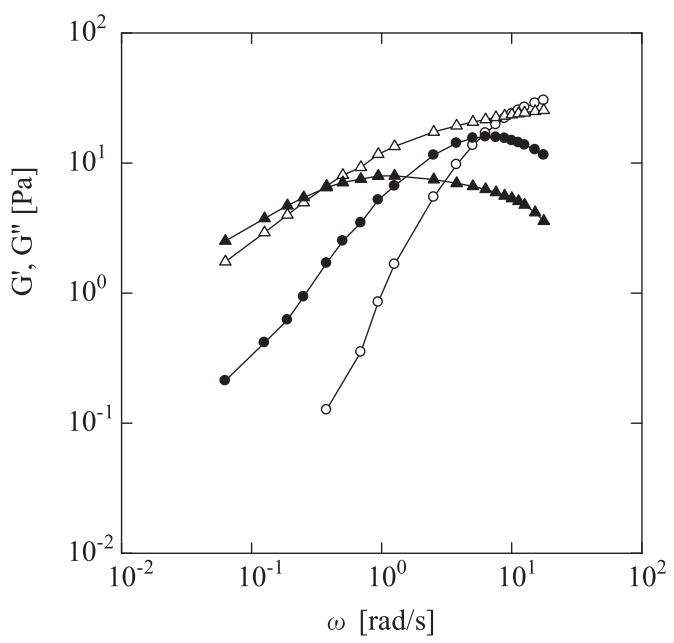

Fig. 6. Viscoelastic properties for 1 wt.\% compounds $6(\bigcirc)$ and 8 $(\triangle)$ dissolved in isododecane. $G^{\prime}$ (open symbols) and $G^{\prime \prime}$ (full symbols) versus angular frequency are shown.

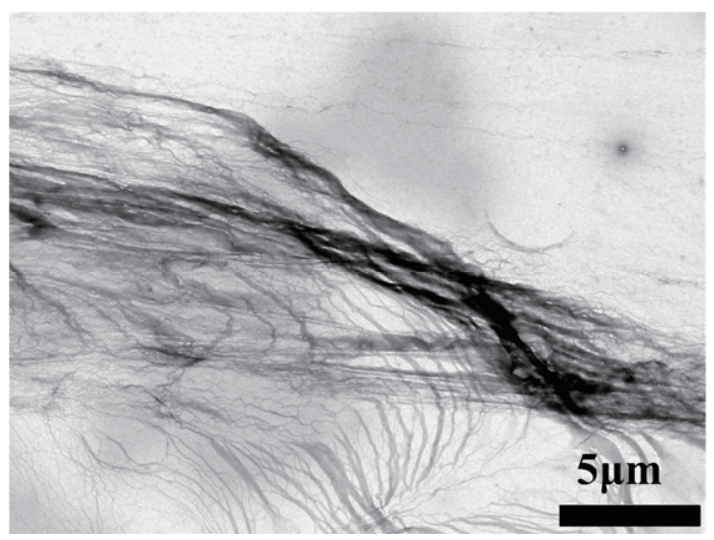

Fig. 7. TEM image of self-assembled structure formed by compound $\mathbf{8}$ in isododecane $(\mathrm{x} 1000)$. the DSC curves of compounds $\mathbf{5}, \mathbf{6}$, and $\mathbf{8}$. Compounds $\mathbf{5}$ and 6 had two absorption peaks on their DSC curves, while compound $\mathbf{8}$ had only one peak. The first peak (A) around $100{ }^{\circ} \mathrm{C}$ and the second peak (B) around $280{ }^{\circ} \mathrm{C}$ might indicate thermal adoption due to crystallization temperature and melting point.
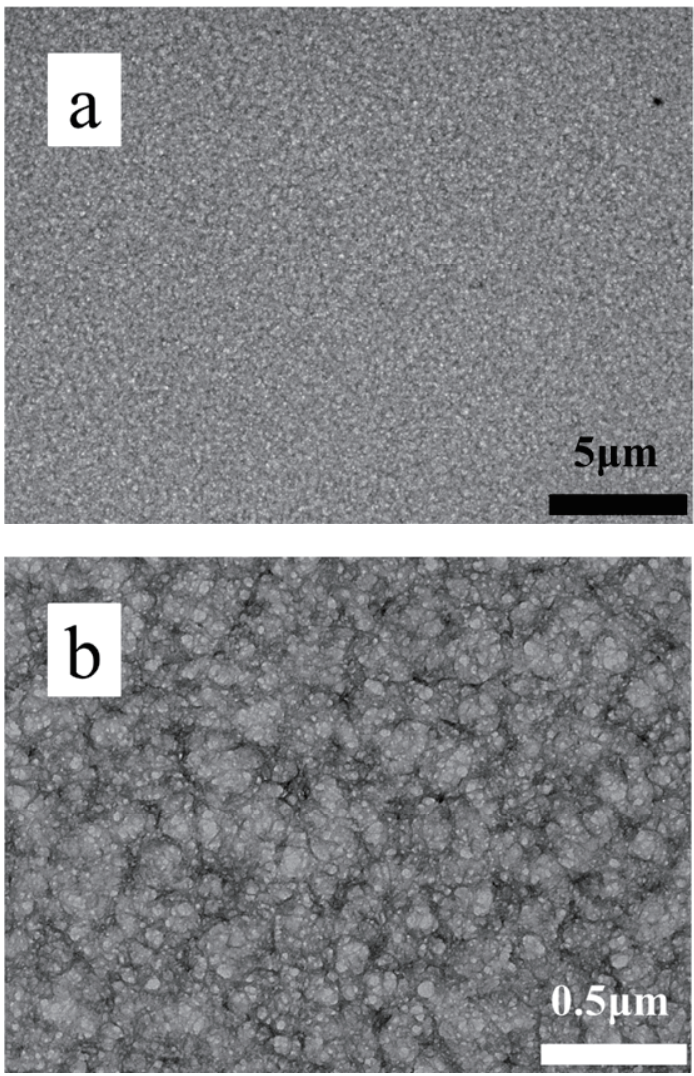

Fig. 8. TEM image of self-assembled structure formed by compound $\mathbf{8}$ in trioctanoin, (a) x1000 and (b) x10000.

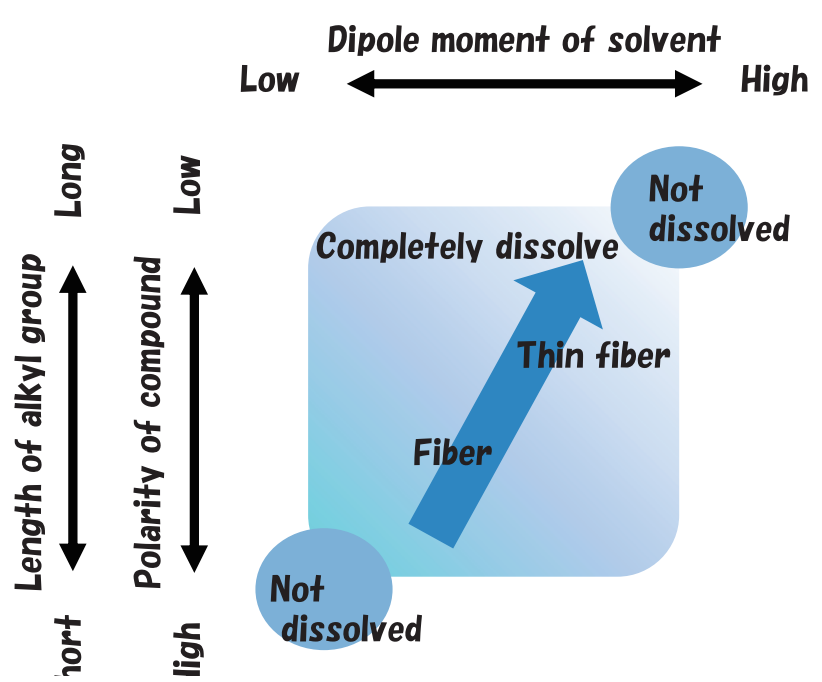

Fig. 9. A schematic view of the relationship between conformation of self-assembled structure and solubility in terms of the polarity of organogelators and dipole moment of solvents. 
Homo-compounds with short alkyl-chains (compound 7) and alkenyl chains (compound 1) had only one peak (peak B). The compound with branch alkyl chains (compound 5) had peak $\mathrm{A}$, at which the temperature was higher than the others. These results indicated the presence of rigid selfassembled structures; as a result, the compound could not be dissolved in most oils. Table $\mathrm{V}$ summarizes the crystallization temperatures, melting points, and calorific values of compounds 1-17 measured with DSC. Since homocompounds 2-4, and $\mathbf{6}$ also had individual crystallization temperatures, their solubility seemed to be lower. Also, despite having no crystallinity, the solubility of compound 7 showed lower value. Therefore, the solubility of pyromellitamide might be related to length of alkyl chain. Hence, solubility and non-crystallinity must be consistent for the purposes of universal organogeletors. Hetero-compounds having either an oleyl group or 2-ethylhexyl groups showed no or little

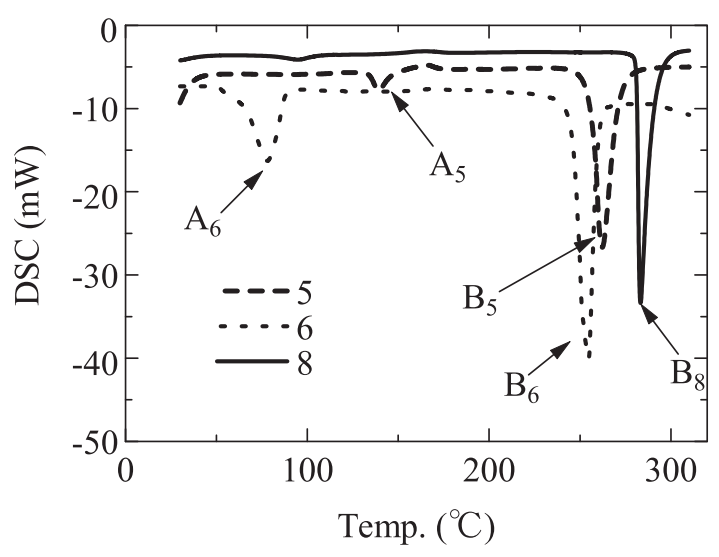

Fig. 10. DSC curves of compounds $\mathbf{5}, \mathbf{6}$, and $\mathbf{8}$.

Table V. Crystallization temperature and Calorific values at the temperatures.

\begin{tabular}{|c|c|c|c|c|}
\hline \multirow[b]{2}{*}{ Compound } & \multicolumn{2}{|c|}{$\mathrm{A}$} & \multicolumn{2}{|c|}{$\mathrm{B}$} \\
\hline & $\begin{array}{r}\text { Crystallization } \\
\text { temperature }\left({ }^{\circ} \mathrm{C}\right)\end{array}$ & $\begin{array}{c}\text { Calorific } \\
\text { value } \\
(\mathrm{kJ} / \mathrm{mol})\end{array}$ & $\begin{array}{c}\text { Melting } \\
\text { point } \\
\left({ }^{\circ} \mathrm{C}\right)\end{array}$ & $\begin{array}{c}\text { Calorific } \\
\text { value } \\
(\mathrm{mJ} / \mathrm{mol})\end{array}$ \\
\hline 1 & - & - & 258.0 & 107.9 \\
\hline 2 & 105.2 & 76.9 & 214.4 & 134.7 \\
\hline 3 & 105.1 & 127.7 & 227.6 & 91.1 \\
\hline 4 & 100.1 & 88.7 & 225.6 & 80.9 \\
\hline 5 & 139.2 & 8.4 & 262.3 & 113.0 \\
\hline 6 & 78.3 & 41.9 & 254.9 & 120.3 \\
\hline 7 & - & - & 280.1 & 151.0 \\
\hline 8 & 94.0 & 4.3 & 283.3 & 113.0 \\
\hline 9 & - & - & 291.4 & 167.4 \\
\hline 10 & 86.8 & 2.5 & 286.8 & 112.1 \\
\hline 11 & - & - & 286.7 & 104.0 \\
\hline 12 & - & - & 316.3 & 126.1 \\
\hline 13 & 101.0 & 4.1 & 270.5 & 111.5 \\
\hline 14 & - & - & 286.1 & 105.9 \\
\hline 15 & - & - & 284.4 & 109.4 \\
\hline 16 & - & - & 283.7 & 108.8 \\
\hline 17 & - & - & 283.3 & 106.2 \\
\hline
\end{tabular}

crystallinity, as was the case with the homo-compounds. Consequently, their solubility for oils seems to be higher to give transparent oil compositions.

The crystallization state of compound 6 at $50-150{ }^{\circ} \mathrm{C}$ with $\mathrm{XRD}$ analysis is shown in Fig. 11. The spacing between repeated structures can be converted from angle of diffraction with Bragg's equation. The peak at $1.6^{\circ}$ shows the spacing in compound 6 between one alkyl chain and another, which can be converted to $27.6 \AA$. The peak at around $10^{\circ}$ seems to reflect the spacing between the compound of one amide group and another. The peak at $2.7^{\circ}$ appears at $80{ }^{\circ} \mathrm{C}$, while that at $1.6^{\circ}$ disappears. These results indicated that the phase transition occurred at around $80^{\circ} \mathrm{C}$, and the spacing between one alkyl chain and another shortened to $16.5 \AA$. The spacing in compound 6 between one amide group and another did not change despite the temperature increasing from $50{ }^{\circ} \mathrm{C}$ to $150^{\circ} \mathrm{C}$. A schematic image of the phase transition of compound $\mathbf{6}$ is shown in Fig.12. The alkyl chains seemed to form the all-trans state at less than $80^{\circ} \mathrm{C}$, and go out of order at more than $80^{\circ} \mathrm{C}$.

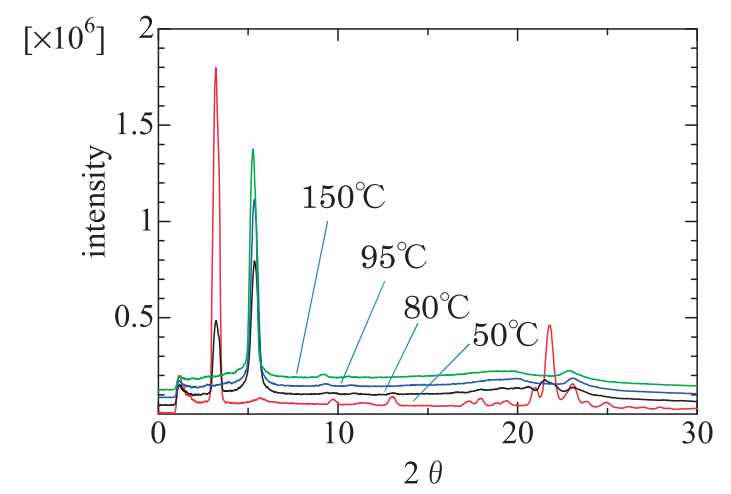

Fig. 11. XRD spectrum of compound $\mathbf{6}$ at different temperatures.

$\underline{25^{\circ} \mathrm{C}}$

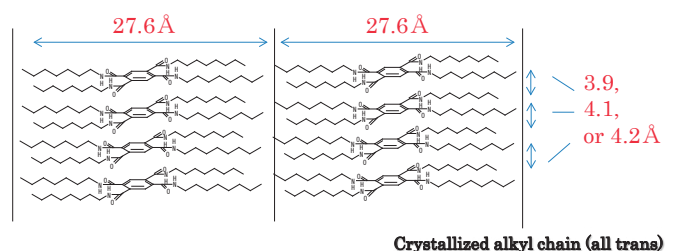

more than $80^{\circ} \mathrm{C}$

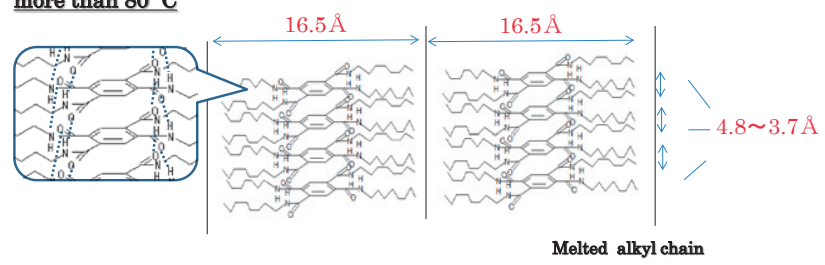

Fig. 12. Self-assembled structure image of compound $\mathbf{6}$ at less or more than phase transition temperature. 
Fig. 13 shows the results of the XRD analysis of compound $\mathbf{8}$. Since phase transition did not occur in compound $\mathbf{8}$ at any temperature between $50{ }^{\circ} \mathrm{C}$ and $150{ }^{\circ} \mathrm{C}$ due to the flexibility of oleyl group, the compound appeared to maintain its solubility even at room temperature.

Although the hydrogen bonding of the amide group within the pyromellitamide may become the core of the selfassembled structure, the role of the chemical side chains is still important. Controlling solubility and crystallinity by the length of side chains consequently controls the affinity of the core molecule to the solvent, which determines the expandability of the self-assembled structure. The degree of the expanse might be related to the interaction of each selfassembled structure. Because a too-high affinity caused instability of the core, suitable conditions are essential. Also, the rheological properties of the compounds are related not only to the degree of entanglement and/ or bridging, but also to the rigidity of the structures, which can in some cases produces viscoelastic properties. From the screening tests conducted in this study, we propose suitable combinations of chemical side chains; however, further research is needed to clarify the relation between chemical structure and rheological properties.

\subsection{Titanium(IV) Oxide - Isododecane Slurries Studies}

Fig.14 shows the equilibrium flow properties of titanium(IV) oxide - isododecane slurries. The sample without an organogelator showed shear thinning properties due to the interaction of coagulated particles. With the addition of compounds $\mathbf{6}$ and $\mathbf{8}$, apparent viscosities increased by a factor of more than one hundred.

Fig. 15 displays the image of titanium(IV) oxide particles

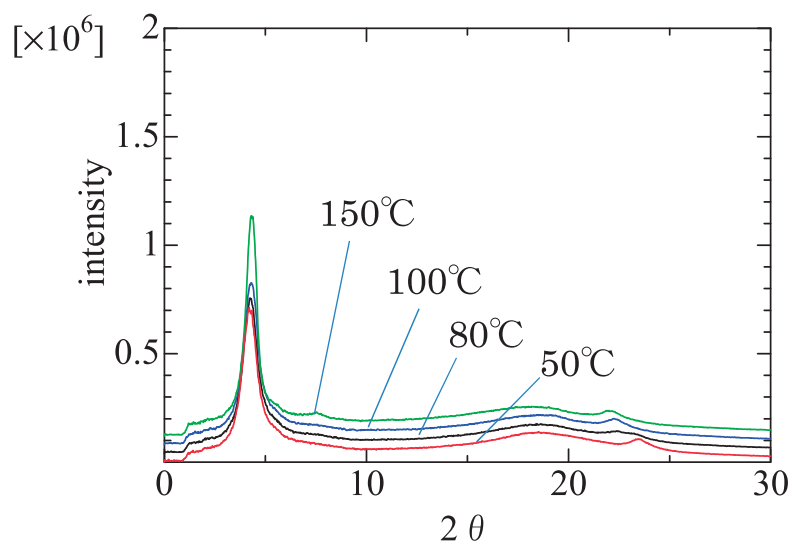

Fig. 13. XRD spectrum of compound $\mathbf{8}$ at different temperatures. in isododecan observed by optical microscope. The sizes of coagulated clusters existing in isododecane were on the order of several microns - the average primary diameter of particles was $16 \mathrm{~nm}$. This means that a sedimentation layer should be formed after a long standstill or under a high centrifuging field due to the significant difference of densities between the particles and the solvent.

The results of sedimentation stability tests for slurries with compounds $\mathbf{6}$ and $\mathbf{8}$ are presented in Table VI. The addition of 0.5 wt.\% compound 6 was effective in keeping the stability of the slurry up to $4000 \mathrm{rpm}$ and increasing the concentration of the compound consequently achieve up to $5000 \mathrm{rpm}$. Compound $\mathbf{8}$ demonstrated the same level of stability

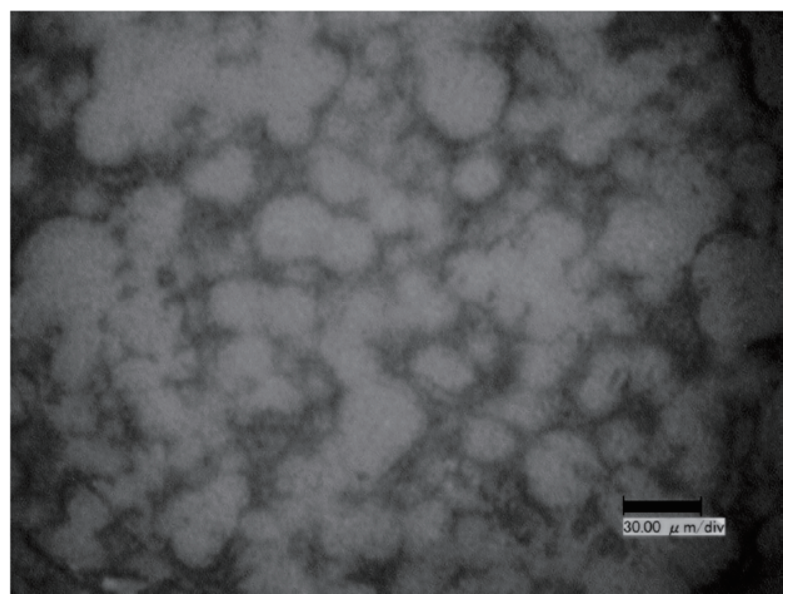

Fig. 14. Titanium(IV) oxide particles in isododecane observed by optical microscope VH-8000 (Keyence Co., Japan).

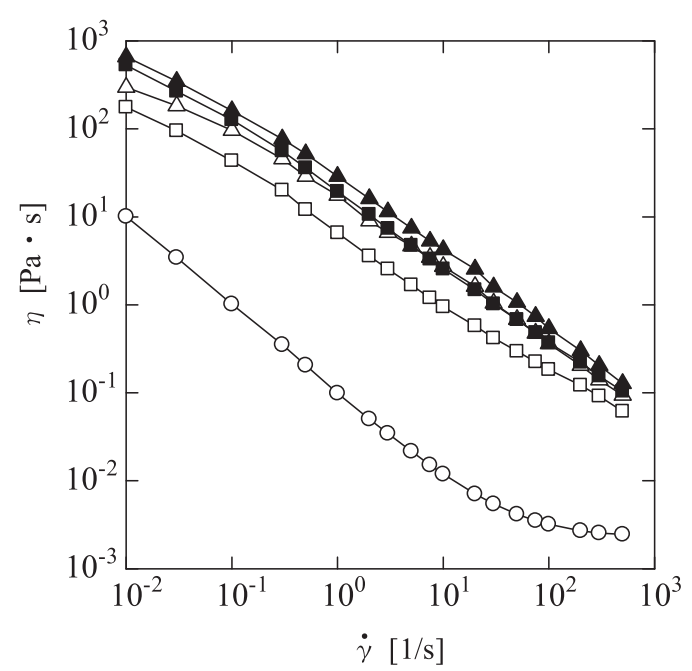

Fig. 15. Equilibrium flow curves for titanium dioxide-isododecane slurries with synthesized compounds $\mathbf{6}$ and $\mathbf{8}$. The solid concentration of the slurry was 15 wt. $\%$. $\bigcirc$ pure slurry; $\triangle 0.5$ wt. $\%$ compound 6 ; A 1.0 wt. $\%$ compound $6, \square 0.5$ wt. $\%$ compound 8 ; 1.0 wt. $\%$ compound 8 . The concentrations of compounds are shown with respect to the solvent weight. 
Table VI. Results of sedimentation stability of titanium(IV) oxide-isododecane slurries with compounds $\mathbf{6}$ and $\mathbf{8}$. Centrifuging force was applied for five min. $\mathrm{G}=9.8 \mathrm{~m} / \mathrm{s}^{2}$. 'stable': no sedimentation, 'unstable': sedimentation.

\begin{tabular}{|c|c|c|c|c|}
\hline \multirow{2}{*}{$\begin{array}{c}\text { Rotational speed } \\
\text { (acceleration) }\end{array}$} & \multicolumn{2}{|c|}{ Compound 6 } & \multicolumn{2}{c|}{ Compound 8 } \\
\cline { 2 - 5 } & $0.5 \mathrm{wt} . \%$ & $1.0 \mathrm{wt.} \%$ & $0.5 \mathrm{wt} . \%$ & $1.0 \mathrm{wt.} \%$ \\
\hline $1000 \mathrm{rpm}$ ( 85G) & stable & stable & stable & stable \\
\hline $2000 \mathrm{rpm}$ ( 340G) & stable & stable & stable & stable \\
\hline $3000 \mathrm{rpm}$ ( 765G) & stable & stable & stable & stable \\
\hline $4000 \mathrm{rpm}(1360 \mathrm{G})$ & stable & stable & stable & stable \\
\hline $5000 \mathrm{rpm}(2126 \mathrm{G})$ & unstable & stable & stable & stable \\
\hline $6000 \mathrm{rpm}(3062 \mathrm{G})$ & unstable & unstable & unstable & stable \\
\hline $7000 \mathrm{rpm}(4147 \mathrm{G})$ & unstable & unstable & unstable & stable \\
\hline $8000 \mathrm{rpm}(5443 \mathrm{G})$ & unstable & unstable & unstable & unstable \\
\hline
\end{tabular}

with half the quantity. 1.0 wt.\% compound 8 successfully maintained stability up to $8000 \mathrm{rpm}(5443 \mathrm{G})$. In spite of lower apparent viscosity with the hetero-compound, the slurry was more stable compared with homo-compound. Thus, stability might be accomplished not only by varying the viscosity of the medium, but also the viscoelastic property, which is considered to be the relaxation effect against the driving force of sedimentation.

\section{CONCLUSION}

N,N',N",N"'-1,2,4,5-tetra alkyl/alkenyl pyromellitamides with two kinds of chains (hetero-compounds) were newly synthesized and evaluated as effective organogelators for organic solvents, compared with homo-compounds. The ability to rheologically control oils might be related to selfassembled structures of the compounds' molecules. We suggested that controlling solubility and crystallinity of compounds are key elements in synthesizing appropriate organogelators. Also, we found that our synthesized organogelators could prevent particle sedimentation of titanium(IV) oxide-isododecane slurries under high acceleration conditions.

\section{REFERENCES}

1) Steed JW, Chem Commun, 47, 1379-1383 (2011).

2) Lehn J-M, Polym Int, 51, 825-839 (2002).

3) Bosman AW, Brunsveld L, Folmer BJB, Sijbesma RP, Meijer EW, Macromol Symp, 201, 143-154 (2003).
4) Brunsveld L, Folmer BJB, Meijer EW, Sijbesma RP, Chem Rev, 101, 4071-4098 (2001).

5) Ciferri A, Macromol Rapid Commun, 23, 511-529 (2002).

6) Velten U, Rehahn M, Chem Commun, 2639-2640 (1996).

7) Hofmeier H, Hoogenboom R, Wouters MEL, Schubert US, J Am Chem Soc, 127, 2913-2921 (2005).

8) Hilger C, Stadler R, Macromolecules, 23, 2095-2097 (1990).

9) De Greef TF, Smulders MMJ, Wolffs M, Schenning AP, Sijbesma RP, Meijer EW, Chem Rev, 109, 5687-5754 (2009).

10) Terech P, Weiss RG, Chem Rev, 97, 3133 (1997).

11) Bouteiller L, Adv Polym Sci, 207, 79-112 (2007).

12) Jang W-D, Aida T, Macromolecules, 37, 7325-7330 (2004).

13) Hanabusa K, Suzuki M, SEN'I GAKKAISHI, 65, 159-165 (2009).

14) Hanabusa K, Koto C, Kimura M, Shirai H, Kakehi A, Chem Let, 429-430 (1997).

15) Nagarajan V, Pedireddi VR, Cryst Growth Des, 14, 1895-1901 (2014).

16) Smulders M, Schenning A, Meijer E, J Am Chem Soc, 130, 606-611 (2008).

17) Wilson A, Gestel J, Sijbesma R, Meijer E, Chem Commun, 42, 4404-4406 (2006).

18) Stals P, Smulders M, Martin-Rapun R, Palmans A, Chem Eur J, 15, 2071-2080 (2009).

19) Tanaka M, Ikeda T, Mack J, Kobayashi N, Haino T, J Org Chem, 76, 5082-5091 (2011).

20) Jimenez CA, Belmar JB, Hidalgo LOP, Fabelo O, Pasan J, Ruiz-Perez C, Cryst Growth Des Comn, 9, 4987-4989 (2009).

21) Tzeng B, Chen B, Yeh H, Lee G, Peng S, New J Chem, 30, 1087-1092 (2006).

22) Rajput L, Chernyshev V, Biradha K, Chem Commun, 46, 6530-6532 (2010).

23) Stals P, Haveman P, Martın-Rapun R, Fitie A, Palmans A, Meijer E, J Mater Chem, 19, 124-130 (2009).

24) Roosma J, Mes T, Leclere P, Palmans A, Meijer E, J Am Chem Soc, 130, 1120-1121 (2008).

25) Inoue D, Sakakibara Y, Suzuki M, Shirai H, Kurose A, Hanabusa K, Chemistry Letters, 34, 348-349 (2005).

26) Shikata T, Kuruma Y, Hanabusa K, Nihon Reoroji Gakkaishi, 39, 119-125 (2011).

27) Webb JEA, Crossley MJ, Turner P, J Am Chem Soc, 129, 7155-7162 (2007).

28) Tong KWK, Dehn S, Webb JEA, Nakamura K, Braet F, Langmuir, 25, 8586-8592 (2009).

29) Sakanishi T, Narusaka $Y$, Itoh M, Saeki T, Nihon Reoroji Gakkaishi, 42, 185-190 (2014). 